\title{
High Temperature Gas Reactors: Assessment of Applicable Codes and Standards
}

\author{
BK Mcdowell JR Nickolaus \\ MR Mitchell GL Swearingen \\ R Pugh
}

October 2011

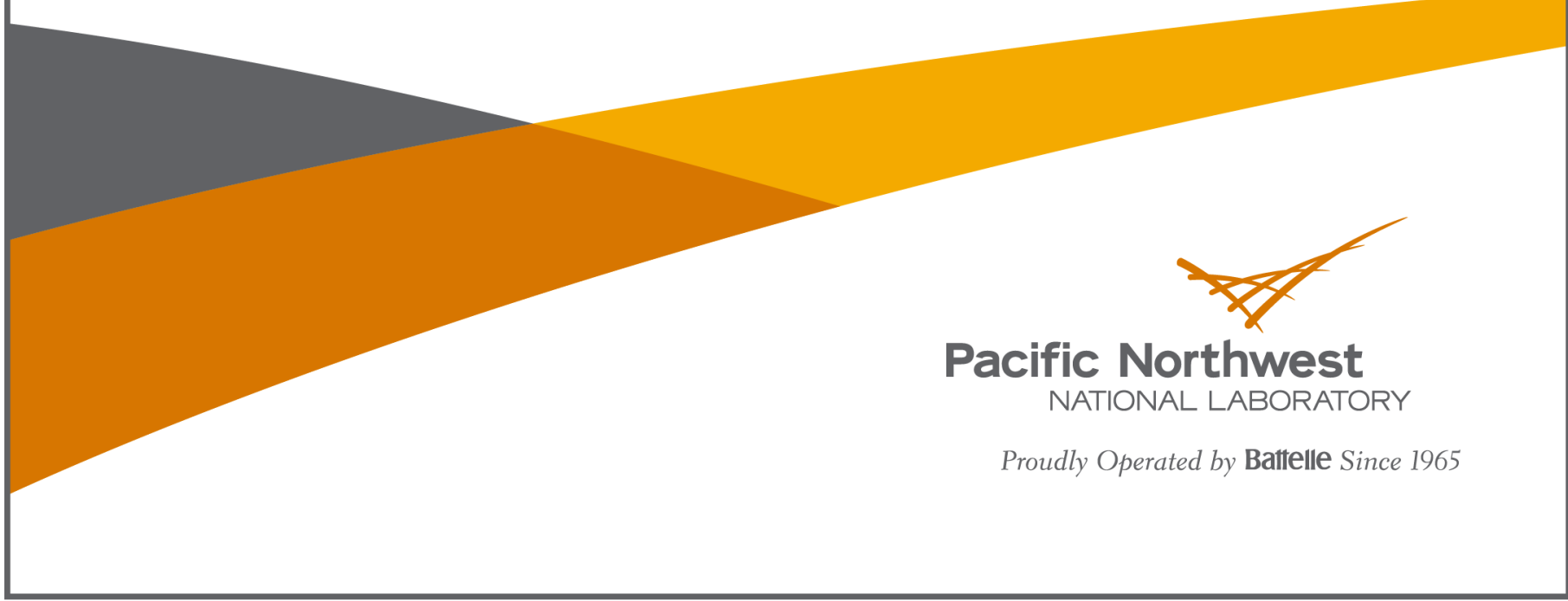




\title{
DISCLAIMER
}

This report was prepared as an account of work sponsored by an agency of the United States Government. Neither the United States Government nor any agency thereof, nor Battelle Memorial Institute, nor any of their employees, makes any warranty, express or implied, or assumes any legal liability or responsibility for the accuracy, completeness, or usefulness of any information, apparatus, product, or process disclosed, or represents that its use would not infringe privately owned rights. Reference herein to any specific commercial product, process, or service by trade name, trademark, manufacturer, or otherwise does not necessarily constitute or imply its endorsement, recommendation, or favoring by the United States Government or any agency thereof, or Battelle Memorial Institute. The views and opinions of authors expressed herein do not necessarily state or reflect those of the United States Government or any agency thereof.

\author{
PACIFIC NORTHWEST NATIONAL LABORATORY \\ operated by \\ BATTELLE \\ for the \\ UNITED STATES DEPARTMENT OF ENERGY \\ under Contract DE-AC05-76RL01830
}

Printed in the United States of America
Available to DOE and DOE contractors from the
Office of Scientific and Technical Information,
P.O. Box 62, Oak Ridge, TN 37831-0062;
ph: (865) 576-8401
fax: (865) 576-5728
email: reports@adonis.osti.gov

Available to the public from the National Technical Information Service

5301 Shawnee Rd., Alexandria, VA 22312

ph: (800) 553-NTIS (6847)

email: orders@ntis.gov <http://www.ntis.gov/about/form.aspx>

Online ordering: http://www.ntis.gov 


\title{
High Temperature Gas Reactors: Assessment of Applicable Codes and Standards
}

\author{
BK Mcdowell JR Nickolaus \\ MR Mitchell GL Swearingen \\ R Pugh
}

Month 2011

Prepared for the U.S. Nuclear Regulatory Commission under an Interagency Agreement with the U.S. Department of Energy Contract DE-AC05-76RL01830

Pacific Northwest National Laboratory

Richland, Washington 99352 


\section{Summary}

Current interest expressed by industry in HTGR plants, particularly modular plants with power up to about $600 \mathrm{MW}(\mathrm{e})$ per unit, has prompted NRC to task PNNL with assessing the currently available literature related to codes and standards applicable to HTGR plants, the operating history of past and present HTGR plants, and with evaluating the proposed designs of RPV and associated piping for future plants.

Considering these topics in the order they are arranged in the text, first the operational histories of five shut-down and two currently operating HTGR plants are reviewed, leading the authors to conclude that while small, simple prototype HTGR plants operated reliably, some of the larger plants, particularly Fort St. Vrain, had poor availability. Safety and radiological performance of these plants has been considerably better than LWR plants. Petroleum processing plants provide some applicable experience with materials similar to those proposed for HTGR piping and vessels.

At least one currently operating plant - HTR-10 - has performed and documented a leak before break analysis that appears to be applicable to proposed future US HTGR designs.

Current codes and standards cover some HTGR materials, but not all materials are covered to the high temperatures envisioned for HTGR use. Codes and standards, particularly ASME Codes, are under development for proposed future US HTGR designs. A "roadmap" document has been prepared for ASME Code development; a new subsection to section III of the ASME Code, ASME BPVC III-5, is scheduled to be published in October 2011.

The question of terminology for the cross-duct structure between the RPV and power conversion vessel is discussed, considering the differences in regulatory requirements that apply depending on whether this structure is designated as a "vessel" or as a "pipe". We conclude that designing this component as a "pipe" is the more appropriate choice, but that the ASME BPVC allows the owner of the facility to select the preferred designation, and that either designation can be acceptable. 


\section{Acronyms and Abbreviations}

AGR

ASME

ASME BPVC

ASTM

ATR

AVR

BISO

DOE

FSV

GT-MHR

HTGR

HTR-10

HTTR

HTR-NPR

INL

ISI

LBB

LWR

MHTGR

NGNP

NRC

PBMR

PCRV

PNNL

PRA

PyC

RPV

SSC

THTR

TRISO

VHTR
Advanced Gas-cooled Reactor

American Society of Mechanical Engineers

ASME Boiler and Pressure Vessel Code

American Society for Testing and Materials International

Advanced Test Reactor

Arbeitsgemeinschaft Versuchsreaktor (Working Group Test Reactor)

bistructural isotropic

U.S. Department of Energy

Fort St. Vrain

Gas Turbine-Modular Helium Reactor

high temperature gas reactor

High Temperature Test Reactor (China)

High Temperature Test Reactor (Japan)

High Temperature Gas Reactor-New Production Reactor

Idaho National Laboratory

in-service inspection

leak-before-break

light water reactor

modular high temperature gas-cooled reactor

Next Generation Nuclear Plant

U.S. Nuclear Regulatory Commission

Pebble Bed Modular Reactor

prestressed concrete reactor vessel

Pacific Northwest National Laboratory

Probabilistic Risk Assessment

pyrolitic carbon

reactor pressure vessel

structures, systems, and components

Thorium High Temperature Reactor

tristructural-isotropic

very high temperature reactor 


\section{Contents}

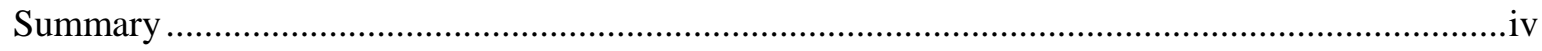

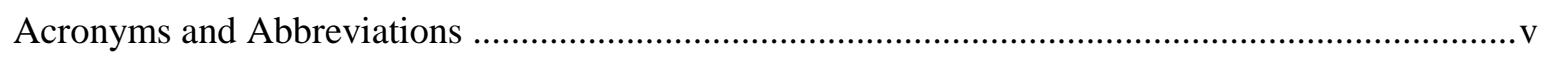

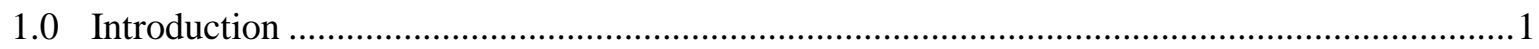

2.0 Operational History of Seven Well-Known HTGR Power Plants ..........................................2

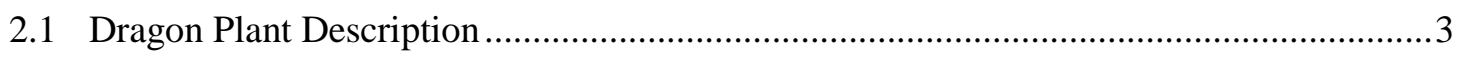

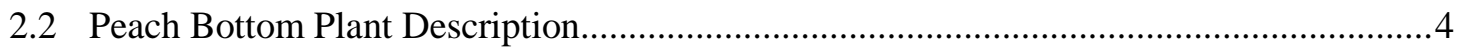

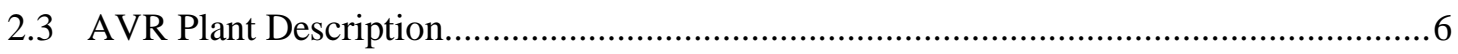

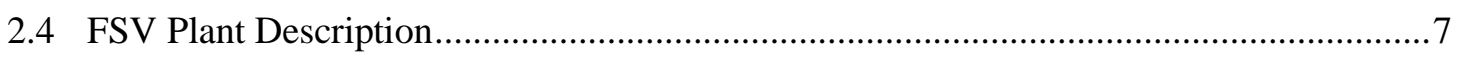

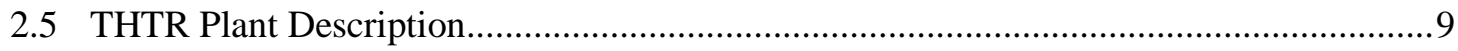

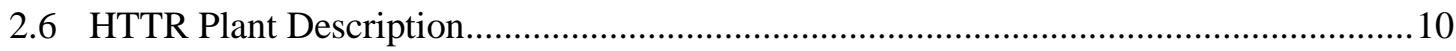

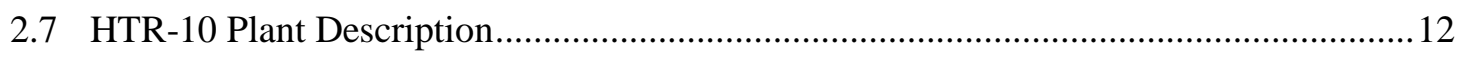

2.8 Non-Nuclear Operating Experience Applicable to HTGR ............................................ 13

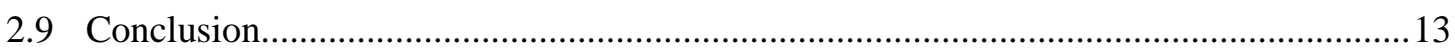

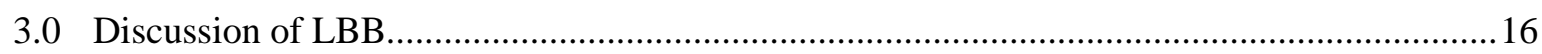

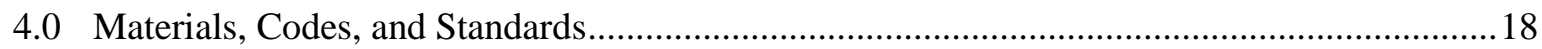

4.1 Classification of Components, Nameplates, Stampings, and Reports............................18

4.2 ASME Code Rules Roadmap for HTGR Plants..........................................................19

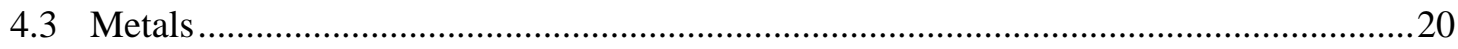

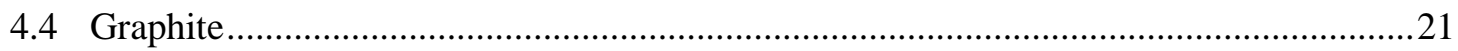

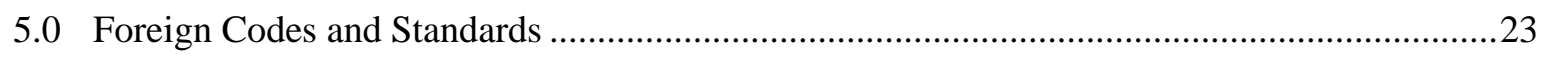

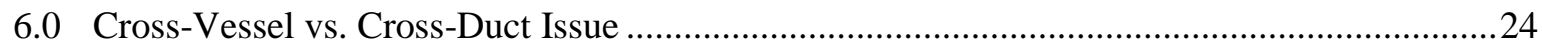

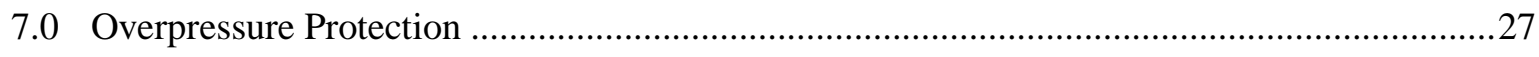

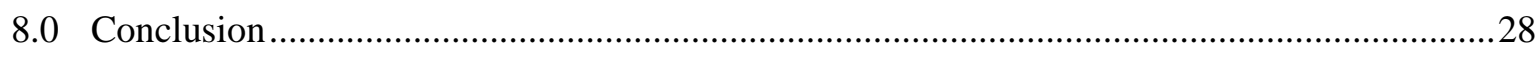

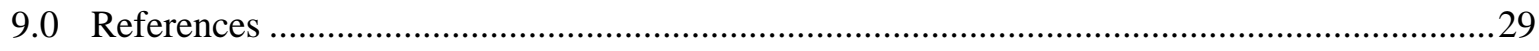




\section{Figures}

Figure 1. Bar Chart of Construction and Operational Time Frames of Seven HTGR Power Plants .2

Figure 2. HTTR Fuel and Reactor Construction Details............................................................ 12

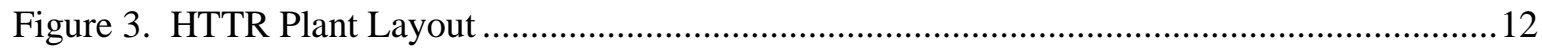





\subsection{Introduction}

This report summarizes the existing literature on high temperature gas cooled reactors (HTGRs) in terms of operational history, leak-before break (LBB) analysis, materials, codes and standards, and preferred terminology for the two large vessel configurations proposed for the Gas Turbine-Modular Helium Reactor (GT-MHR) and similar HTGR plants proposed for the near future.

Current interest expressed by industry in HTGR plants, particularly modular plants with power up to about 600 MW(e) per unit, has prompted the U.S. Nuclear Regulatory Commission (NRC) to task Pacific Northwest National Laboratory with assessing the currently available literature related to codes and standards applicable to HTGR plants, summarizing the operating history of past and present HTGR plants, and evaluating the proposed designs of reactor pressure vessel (RPV) and associated piping for future plants.

This document reviews the operational histories of five decommissioned and two currently operating HTGR plants. Safety and radiological performance of these plants is noted. Additionally, this document examines the LBB concept as applied to HTGR plants and next considers the materials that have been used and are proposed for new construction, as well as the codes and standards applicable to HTGR plants. Finally, terminology for the cross-duct component between the RPV and power conversion vessel is discussed, considering the important differences in regulatory requirements that apply depending on whether this structure is designed as a vessel or as a pipe.

Petroleum processing plants provide some applicable experience with materials similar to those proposed for HTGR piping and vessels. 


\subsection{Operational History of Seven Well-Known HTGR Power Plants}

While several smaller, lesser known gas cooled reactors have been built and operated, the seven plants considered here have the most operational history available and are more similar to proposed future units than the few other units mentioned in literature.

Goodjohn (1991) states the defining characteristics of HTGRs as ceramic fuel, graphite moderator, and helium coolant. Based on this definition, the British $\mathrm{CO}_{2}$ cooled reactors, both the lower-temperature Magnox and the higher temperature advanced gas cooled reactors, are not HTGR plants.

Gas-cooled nuclear reactors were first proposed in 1942 by Farrington Daniels, a professor of chemistry at the University of Wisconsin. His first report on the topic was published in 1944 (Daniels 1944).

Current design features such as having most of the plant below grade, a direct cycle turbine, and pebble bed cores are all concepts originally proposed by Daniels (Simnad 1991).

Figure 1 shows the approximate dates of construction, operation, and major outages for the HTGR plants. All of these plants except Dragon (Winfrith, England) and HTTR (Tokaimura, Japan) were equipped to generate electricity, although AVR (Julich Research Center, West Germany), Peach Bottom (Delta, near Harrisburg, Pennsylvania), and HTR-10 (Tsinghua University,Beijing, China) were all small enough that they can be considered prototype plants rather than as commercial power plants intended to make a profit.

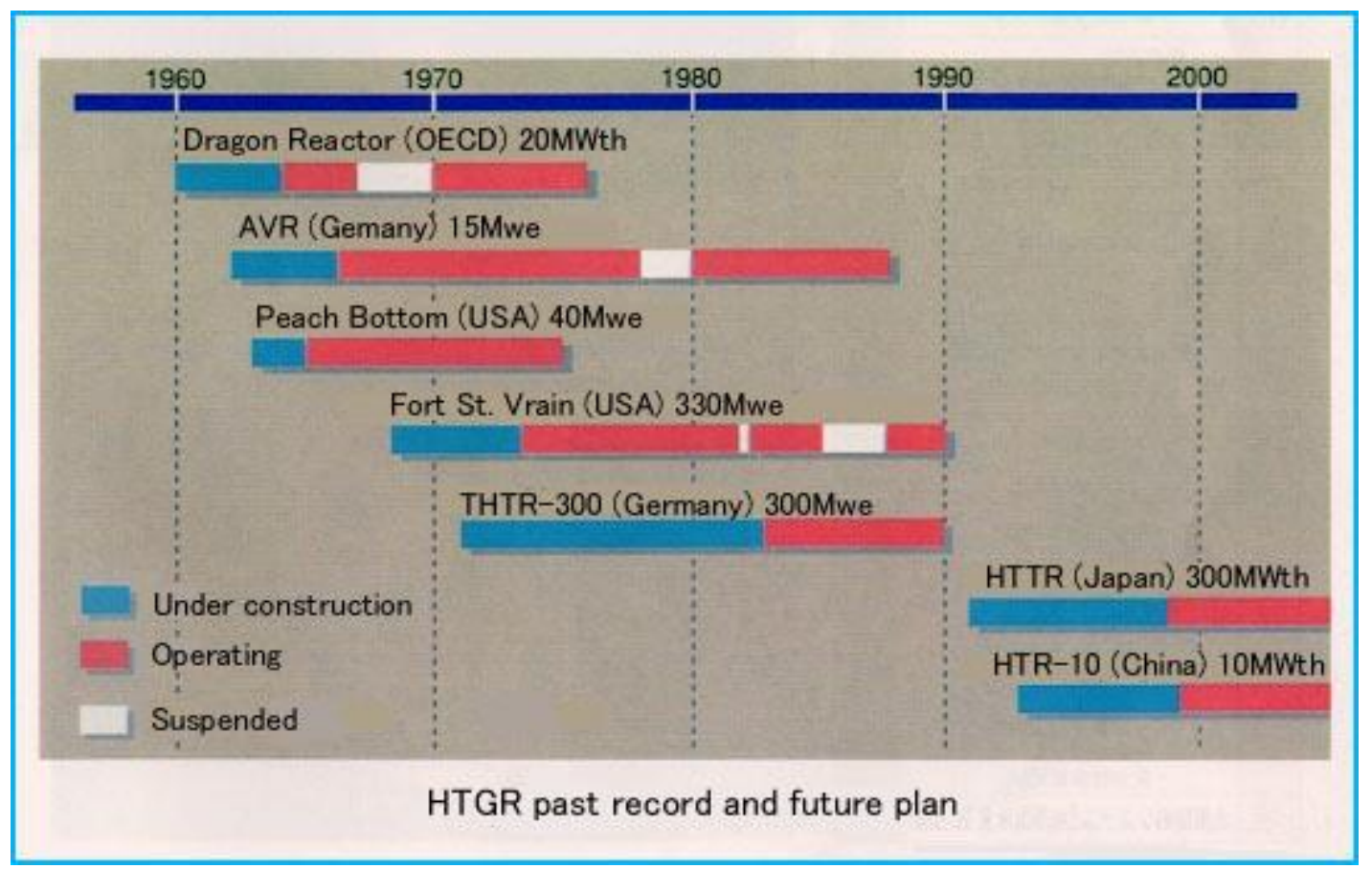

Figure 1. Bar Chart of Construction and Operational Time Frames of Seven HTGR Power Plants (Source: http://www.jaea.go.jp/jaeri/english/ff/ff43/randd01.html)

To date, HTGR plant history can be considered as two generations: the first generation, from 1960 to 1990, were American and European (mostly German) plants that were all shut down by 1991; and a 
second generation of Asian plants, both of which are still operating as of this writing. In the United States, besides the Peach Bottom and Fort St. Vrain (FSV) plants that were built and operated, paper studies were performed on several proposed HTGR plants, starting with the 10 large HTGR reactor plants (five stations, each with two reactors) sold by General Atomics between 1971 and 1974. Licensing documents, including construction permit safety evaluation reports and letters from the Advisory Committee on Reactor Safeguards, were prepared for two of these (the Fulton and Summit plants), although none of these large plants were ever built. Docket numbers were assigned for Fulton (50464) and Summit (50463); (Beck et al. 2010). A U.S. Department of Energy (DOE)-sponsored HTGR program began in the late 1970s, initially focused on a plant of $840 \mathrm{MW}(\mathrm{t})$ with a once-through low enriched uranium/thorium fuel cycle. In the mid-1980s, DOE turned to a smaller modular design (a modular HTGR) with an annular core and steel RPV, and a conceptual design was completed in 1987. Draft Preapplication Safety Evaluation Report for the Modular High-Temperature Gas-Cooled Reactor (NUREG-1338) was written in early 1989. During the late 1980s, the modular HTGR was considered by DOE as one of two possible reactor technologies for materials production (Goodjohn 1991). Preliminary design work was performed on this modular HTGR-NPR, but the plant, originally expected to start in 1998, was never built (Hoffman and Mears 1991).

Four of the seven plants constructed and operated used prismatic block fuel; the remaining three used pebble bed fuel. The operational experience considered in this report does not show any obvious advantages to either fuel type.

Sections 2.1 through 2.7 present an overview of the operational experience for seven HTGR power plants. The plants are presented in the chronological order of their initial operation, from Dragon in 1964 to HTR-10 in 2000.

\subsection{Dragon Plant Description}

Key Specifications (from Beck et al. 2010):

- Thermal Power: 21.5 MW

- Power Density: $14 \mathrm{MW} / \mathrm{M}^{3}$

- Secondary Coolant: Steam (low quality steam and hot water)

- Primary System Pressure: $2 \mathrm{MPa}$

- Primary Inlet Temperature: $350 \mathrm{C}$

- Primary Outlet Temperature: $750 \mathrm{C}$

- Vessel Material: Carbon Steel

- Core Type: Prismatic Blocks

- Years of Operation: 1964-1975

Dragon was located in Winfrith, England. Dragon was the first HTGR, built in the United Kingdom strictly as a fuel and materials test reactor. It was never intended to generate electric power and did not have any power-conversion equipment. With only one vessel, the RPV, no cross-vessel was used in construction. (Simon 2005). 
The primary circuit at Dragon was the first one to use "cold" helium returning from the heat exchangers to maintain the vessel at a temperature several hundred degrees Celsius lower than the "hot" helium temperature. This was done to limit creep of the carbon steel reactor pressure vessel (Simon and Capp 2002).

The original design of the Dragon fuel was intended to release some volatile fission products into a purge flow of helium gas (Simnad 1991). The purpose of this was to intentionally release xenon and krypton and remove these neutron poisons from the core. Experience revealed that, even at temperatures up to $1000 \mathrm{C}$, the fuel retained most of the xenon and krypton generated. This led to the development of tristructural-isotropic (TRISO) type coated particle fuel, which releases only $10^{-7}$ of the fission products generated (Simon and Capp 2002).

Dragon's original fuel load was a highly enriched uranium/thorium fuel, but due to questions about longterm availability of highly enriched uranium in the United Kingdom, this was replaced by low-enriched $(3.5 \%)$ uranium fuel (Beck et al. 2010).

Dragon rejected heat through six circulator/heat exchanger branch circuits. These were cooled by water at 15.8 bar pressure (lower than the 20 bar primary helium pressure to prevent significant water injection in the event of a tube leak) entering the heat exchanger at $200 \mathrm{C}$ and leaving it with a steam content of $16.4 \%$ by weight. This secondary circuit was cooled in turn by a tertiary water circuit pressurized to 13 bar with cold and hot temperatures of $50 \mathrm{C}$ and $187 \mathrm{C}$, respectively. This rejected heat to the atmosphere via a bank of fin-fan dry coolers (Simon 2005).

\subsection{Peach Bottom Plant Description}

Key Specifications (from Beck et al. 2010):

- Thermal Power: $115 \mathrm{MW}$

- Power Density: 8.3 MW/M ${ }^{3}$

- Secondary Coolant: Steam (modern fossil steam conditions, no reheat)

- Primary System Pressure: $2.3 \mathrm{MPa}$

- Primary Inlet Temperature: $327 \mathrm{C}$

- Primary Outlet Temperature: 700-726 C

- Vessel Material: Carbon Steel

- Core Type: Prismatic Blocks

- Years of Operation: 1966-1974

Peach Bottom Unit 1 was located in Delta, near Harrisburg, Pennsylvania. Peach Bottom Unit 1 was the first HTGR to operate in the United States, and it was first in the world to produce electrical power. It operated successfully for 8 years as a prototype reactor, demonstrating high thermal efficiency power generation and the highly enriched uranium/thorium converter fuel cycle that was subsequently used at FSV (Simnad 1991). 
Peach Bottom used a fuel element made of a sleeve of low-permeability graphite with a fuel bearing midsection in the center, with top and bottom reflectors. The plant featured a purge helium system to remove fission products from the fuel elements. The early fuel designs were expected to release a significant fraction of fission products, the plant featured a purge helium system similar to the one used at Dragon. (Simnad 1991).

Because Peach Bottom featured up-flow of helium coolant through the core; decay heat could be removed by natural circulation using the service steam generators. The plant did not have a dedicated decay heat removal system; instead the main circulator was run using a "pony" motor. The plant had a steel containment, which was inserted during operation. Reactivity control was by solid absorber rods with one of three types of actuators: pneumatic accumulators, electric drive, or thermal fuse/gravity inserted (Fisher and Orvis 1981).

One operational problem documented at Peach Bottom was fission product release from the earliest loads of fuel. These were made with a simple fuel particle: the uranium or thorium "kernel" was coated with a single layer of pyrolitic carbon (also known as PyC). This led to replacement fuel being made with a bistructural isotropic (BISO) fuel particle with an inner buffer layer to accommodate fission product recoil and an outer layer to retain noble gas fission products (Beck et al. 2010). Core 1, the original fuel load, featured the simple single-coated particles and operated from initial criticality until June 1970; Core 2 featured BISO particles and released less fission product inventory than Core 1. Core 1 reached a burnup of 30,000 MWd/MTu, at which point fuel swelling occurred, leading to cracking of the fuel element sleeves. Core 2 operated from mid-1970 to October 1974 (Simnad 1991).

Another operational problem was oil ingress from the oil-lubricated bearings of the helium compressors (circulators). Near the end of Core 1's life, concerns about oil ingress were raised. Investigation revealed that the demister/filter on the outlet of the compressor had become saturated with oil and that approximately $100 \mathrm{~kg}$ of oil entered the reactor. The oil caused carbon deposits on primary circuit metal surfaces and persistent hydrogen and methane impurities in the primary coolant (Beck et al. 2010).

The Peach Bottom plant had an overall capacity factor of $75 \%$, considered high for a prototype plant (Simnad 1991). Exclusive of planned shutdowns for research and development programs, the capacity factor was $88 \%$ (Goodjohn 1991). The steam generators were the first nuclear steam generators to use Alloy 800; no leaks or failures of the steam generators were experienced during seven years of plant operation (Simnad 1991).

Peach Bottom was the first HTGR plant constructed with a "cross-vessel" connecting the reactor vessel to a steam generator; in fact, it had two such components (Beck et al. 2010).

Peach Bottom had completed its demonstration mission by the end of October 1974. By that time, Core 2 had been expended, and a decision had to be made to apply for a permanent operating license for continued operation. A study conducted by Philadelphia Electric Company (cited in Beck et al. 2010) indicated that the benefits of continued operation beyond Core 2's life would not exceed expenses to do so. The plant turned out to be too small to be commercially viable; as a result, it was shut down and decommissioned (Beck et al. 2010). 


\subsection{AVR Plant Description}

Key Specifications (from Beck et al. 2010):

- Thermal Power: $46 \mathrm{MW}$

- Power Density: 2.6 MW/M ${ }^{3}$

- Secondary Coolant: Steam (modern fossil steam conditions, no reheat)

- Primary System Pressure: 1.1 MPa

- Primary Inlet Temperature: $275 \mathrm{C}$

- Primary Outlet Temperature: $950 \mathrm{C}$

- Vessel Material: Steel and Concrete Building

- Core Type: Pebble Bed

- Years of Operation: 1967-1988

AVR was located at the Julich Research Center in Germany. AVR was one of the first reactors built in the Federal Republic of Germany. It used a "pebble bed" type core, with the fuel contained in $6 \mathrm{~cm}$ diameter graphite spheres. These spheres contain the TRISO and BISO fuel particles in the center $4 \mathrm{~cm}$ region of the fueled spheres. The initial core consisted of approximately 30,000 fueled and 70,000 additional non-fueled graphite spheres. During operation, the spheres were circulated out of the reactor, where the fueled spheres were evaluated for burn-up by means of a high-resolution gamma spectrometer. The spheres with high enough burn-up were removed from the reactor; spheres with sufficient remaining fuel were returned (Simnad 1991).

AVR operated successfully for 20 years and reached temperatures of up to $1000 \mathrm{C}$, the highest of any commercial reactor to date (Simnad 1991). AVR operated with an average availability of $66.4 \%$ and generated 1.67 billion KWh of electricity (Goodjohn 1991).

One of the most significant operational occurrences at AVR was a steam generator leak that developed at the beginning of or during a 1978 plant shutdown to repair a safety valve. AVR normally experienced some increase in helium moisture during shutdown; in this case when the reactor was restarted, the moisture levels increased enough to require plant shutdown. Investigation revealed that a 1 to $3 \mathrm{~mm}^{2}$ leak had formed in one steam generator. Since the steam generators were located above the core, this leak resulted in a significant amount of water in the system. Because AVR did not have a low-point drain to remove bulk water from the vessel, removal of the water and repair of the steam generator required a 15month shutdown. AVR did not use a cross-vessel type of construction, instead having the steam generators above the core in a single vessel (Beck et al. 1991).

Toward the end of operation, AVR's availability was increasingly affected by testing programs (although availability was impacted by testing programs from the beginning of operation). Tests included loss of forced cooling; the pebble bed fuel remained below temperatures that could cause fuel failure, as measured by instrumented graphite spheres with wires with melting points from 600 to $1280 \mathrm{C}$ (Marnet et al. 1991). 


\subsection{FSV Plant Description}

Key Specifications (from Beck et al. 2010):

- Thermal Power: 842 MW

- Power Density: 6.3 MW/M ${ }^{3}$

- Secondary Coolant: Steam

- Primary System Pressure: 4.8 MPa

- Primary Inlet Temperature: $404 \mathrm{C}$

- Primary Outlet Temperature: $777 \mathrm{C}$

- Vessel Material: Prestressed Concrete Reactor Vessel (PCRV)

- Core Type: Prismatic Block

- Years of Operation: 1976-1989

FSV was located in Pletteville, Colorado. FSV, the only commercial HTGR to operate in the United States, was built under the Atomic Energy Commission Reactor Demonstration Program (Brey 1991). Unlike pressurized water reactor and boiling water reactor plants, FSV generated steam at typical modern fossil plant single reheat temperatures and pressures: 2400 PSI main steam at $1000 \mathrm{~F}$, with a single reheat to $1000 \mathrm{~F}$, with six stages of regenerative feed-water heating (Benham et al. 1973). The main turbine was essentially a regular single-reheat fossil turbine with the exception that steam flowed to the helium circulator drive turbines before going to the reheat section of the steam generators (Benham et al. 1973).

The construction of the plant featured the entire primary circuit inside the PCRV, including the reactor core, four steam driven helium circulators, and 12 once-through steam generators (two loops of six each) with reheat, so no cross-vessel type structures were used (Benham et al. 1973). As such, the reactor vessel at FSV was completely different in construction and in terms of the codes and standards it met for nuclear use when compared to U.S. LWR plants and to the Peach Bottom Unit 1 prototype, which all have or had steel reactor vessels.

The overall layout of the reactor core was similar to the proposed design of the GT-MHR. The FSV core featured 37 individually regulated flow regions with adjustable orifices at the inlet of each region. These were adjusted by control room operators to equalize outlet temperatures in the regions (Brey 1991).

FSV was seldom run at $100 \%$ rated power for several reasons. Initial rise to power testing revealed core fluctuations above about $70 \%$, apparently due to combined thermal/hydraulic effects; this continued for the next 2.5 years. The plant required its first refueling before full-power operation could be achieved. The fluctuations were stopped by installing constraining devices connecting the upper fuel elements of adjacent refueling regions of the core in a separate shutdown in late 1979. Following this, FSV operated at rated power for the first time on November 6, 1981. From 1981 to 1983, the plant operated at up to $100 \%$ power, with major shutdowns for the second refueling and a modification of the circulator auxiliary systems. The plant shut down at the end of 1983 for the third (and as it turned out, final) refueling (Brey 1991). 
Regulatory changes associated with Appendix R (to 10 CFR Part 50) Fire Protection imposed power level limits on FSV. After a major shutdown (to make modifications for environmental qualification of electrical components to comply with Subpart 49 of 10 CFR 50) was completed in 1987, NRC limited maximum allowable reactor power to 35\%. This limitation stemmed from concerns about heat removal capability using safe shutdown cooling per the plant Appendix R Fire Protection program; these concerns were based on initial reassessments of the ability to remove decay heat by flooding either the reheat module or economizer-evaporator-superheat module of the main steam system. For the case of the reheat module, the fire water system could only supply enough water volume to flood one module; a single module would not provide enough heat removal capacity to deal with $100 \%$ decay heat. FSV management decided to remove this method of heat removal from the final safety analysis report rather than modify the plant to provide adequate heat removal capability. For the economizer-evaporatorsuperheat module, it was determined that steam binding could occur above $83 \%$ of maximum decay heat; this led to an administrative limit on reactor power that continued to the end of plant operation (Brey 1991).

FSV was plagued by moisture intrusion and limited ability to remove moisture once it got into the primary system. Moisture in the helium coolant was a problem for three main reasons:

- It could attack the graphite fuel assemblies and more importantly the permanent core support blocks, which were made from PGX graphite, which exhibited a higher oxidation rate than the H-327 and H451 graphite used in the fuel elements (FSV final safety analysis report).

- It could cause corrosion of carbon steel components, particularly the control rod drive mechanisms.

- Significant moisture in the helium coolant added positive reactivity. For example, during a moisture intrusion event on June 22, 1984, after control room operators reduced reactor power manually to $30 \%$, moisture ingress raised power to $40 \%$, which contributed to a scram on high vessel pressure at 0029 hours on the June 23. Six control rod pairs failed to insert on this scram-and this was eventually traced to corrosion of the control rod drive mechanisms (Brey 1991).

Moisture ingress from the steam generators and reheaters was less problematic than moisture from the circulator auxiliary systems. A leak occurring in late 1977 in one reheater tube was identified and plugged after a manual reactor scram. The identification of the leaking tube and its plugging were carried out without significant exposure of personnel to radiation (Beck et al. 2010).

There were several important sources of moisture intrusion into the primary system at FSV. Most important were the liner cooling system and the circulators' water-lubricated bearings. The ability of the helium purification system to remove moisture once it got into the system was limited, in part because it was designed to remove small volumes of moisture (NUREG/CR-6839).

Part of the corrective actions associated with LER 50-267/84-008 (cited in NUREG/CR-6839) was a test of the reserve shutdown system; this test was performed in November 1984 and revealed that several hoppers failed to discharge the reserve shutdown balls. This indicated that the reserve shutdown control system, consisting of hoppers with graphite rupture diaphragms and borated graphite balls, was also subject to degradation by moisture intrusion. Low-level moisture intrusion over an extended period of time had the potential to compromise both the control rods and the reserve shutdown system (NUREG/CR-6839). 
On Friday, October 2, 1987, at 2359 hours a fire was identified in the turbine building; the fire was apparently caused by hydraulic oil leaking from a hydraulically controlled valve (HV-2292; Loop II Main Steam Bypass Valve) onto hot steam piping. The fire damaged several pieces of equipment and many electrical cables. Cable damage led to loss of power to the control room radiation monitor, causing an automatic transfer of ventilation to a recirculation mode. This in turn led to some smoke entering the control room and to a trip of one reheat steam radiation monitor, leading to a shutdown of Loop I. Since Loop II had been shut down manually due to the hydraulic valve failure, this caused a loss of forced cooling at 0008 hours on October 3. By 0020 hours, the reheat steam radiation monitors had been bypassed and helium circulation and Loop I secondary flow were restored. This fire is unusual because it was ignited by a steam pipe; LWR reactors do not operate at high enough temperatures to ignite most hydraulic oils. A more typical effect was that fire-induced cable damage caused unexpected control system responses generally similar to the Brown's Ferry Unit 1 fire. The final root cause determination found that a restrictor orifice was left out of a thermal relief for hydraulic valve HV-2292. This caused the relief to open on the normal surge of pressure when the valve was actuated, leading to an increased rate of hydraulic oil discharge and prevented reseating of the valve. The higher-than-normal volumetric rate of hydraulic oil discharge overwhelmed the hydraulic oil containment system for the valve, resulting in the oil spilling onto the hot surfaces of the valve and igniting (LER 50-267/87-023).

FSV suffered from operational problems as noted above and by the mid 1980s was confronted with rising maintenance, operations, and fuel costs. On December 5, 1988 the Board of Directors of the Public Service Company of Colorado decided to shut the plant down on or before June 30, 1990 (Brey 1991). In late August 1989, during a shutdown to repair a faulty control rod drive, a steam leak was discovered in the main steam ring header, and further inspections revealed more cracking. Faced with the considerable expense required to repair the ring header, the company decided to permanently shut FSV down (as a nuclear power plant) on August 29, 1989 (Goodjohn 1991).

FSV generated over 4.8 billion KWh of electricity over its operating life (Goodjohn 1991).

\subsection{THTR Plant Description}

Key Specifications (from Beck et al. 2010):

- Thermal Power: $750 \mathrm{MW}$

- Power Density: $6 \mathrm{MW} / \mathrm{M}^{3}$

- Secondary Coolant: Steam (modern fossil steam conditions, with reheat)

- Primary System Pressure: $4 \mathrm{MPa}$

- Primary Inlet Temperature: $404 \mathrm{C}$

- Primary Outlet Temperature: $777 \mathrm{C}$

- Vessel Material: PCRV with Liner

- Core Type: Pebble Bed

- Years of Operation: 1985-1991 
The Thorium High Temperature Reactor (THTR) was built by an industrial consortium near the city of Hamm Uentrop, in the German state of North Rhine Westphalia. The commissioning program was completed in May 1987, and the plant was turned over to the operating utility on June 1, 1987 (Goodjohn 1991).

Initial criticality was on September 13, 1983, the generator was synchronized to the grid for the first time on November 16, 1985, and full power reached on September 23, 1986 (Baumer and Kalinowski 1991).

In general, the technical performance of THTR was good; part of this can be attributed to the more reliable electric drive circulators. These six circulators, $2300 \mathrm{KWe}$ each, never required a reactor shutdown. The PCRV type construction of THTR did not use any cross-vessel type structure, although it did have a metallic hot duct internal to the PCRV (Beck et al. 2010).

The hot duct of THTR was made of Alloy 617, which contains cobalt. The THTR experience was that the cobalt was not incorporated into an oxide scale, so the cobalt did not enter the hot gas circuit (Beck et al. 2010).

The THTR shut down for planned maintenance in October 1988, and maintenance inspections found that 35 out of about 2600 head hold-down bolts were defective. Technical evaluations of these findings indicated the plant could continue to operate safely, but the plant was not restarted by the utility pending renegotiation of the risk-sharing contract between the members of the consortium. Political considerations of risk-sharing among the Federal, state, and industrial (members of the consortium) stakeholders resulted in a decision not to restart the plant (Goodjohn 1991). Specific issues contributing to the decision not to restart the plant were the increase of financial operating losses to be borne by the utility from $10 \%$ for the first 3 years of operation to $30 \%$ thereafter; increases in the estimated cost of eventual decommissioning; the original fuel manufacturer ceasing to manufacture the fuel pebbles; failure to secure a permanent spent fuel repository agreement; and uncertainties about issuance of a "permanent" operating license after the initial provisional license expired after the first 1100 full-power operating days (Baumer and Kalinowsk 1991).

\subsection{HTTR Plant Description}

Key Specifications (from Beck et al. 2010):

- Thermal Power: $30 \mathrm{MW}$

- Power Density: 2.5 MW/M ${ }^{3}$

- Secondary Coolant: He/Pressurized Water

- Primary System Pressure: $4 \mathrm{MPa}$

- Primary Inlet Temperature: 395 C

- Primary Outlet Temperature: 850-950 C

- Vessel Material: 2-1/4Cr-1Mo Steel

- Core Type: Prismatic Blocks

- Years of Operation: Startup in 1998, still operating as of date of report (2011) 
HTTR is located on the Japanese Atomic Energy Agency campus in the Ibaraki Prefecture, Tokaimura, Japan. HTTR is a prismatic fuel type HTGR reactor featuring a steel RPV connected to heat exchangers that cool the outlet helium (there is no power conversion equipment at this strictly-research reactor) by means of a secondary helium loop. This transfers heat to pressurized water heat exchangers, and these in turn reject heat to the atmosphere. The RPV is connected to the heat-exchanger vessel by a cross-vessel, which in English-language literature refers to as a cross-duct (Shiozawa et al. 2004).

HTTR's website shows that the overall layout of the reactor vessel is similar to the proposed design of the GT-MHR. The RPV is connected to secondary heat exchange vessels by a hot duct inside a cold duct pipe. As shown in Figure 3 below, the bulk of the plant is built below grade.

The plant achieved initial criticality in November 1998 and reached rated power of $30 \mathrm{MW}$ for the first time in December 2001 (Beck et al. 2010).

2-1/4Cr-1Mo Steel is used for the HTTR vessel because it normally operates at about $400 \mathrm{C}$; this alloy has higher creep rupture strength at elevated temperatures than the usual Mn-Mo steels used for light water RPVs. The RPV is built up from three types of components: forgings meeting Japan Industrial Standard (JIS) SFVAF22B, which is equivalent to ASTM A336/A336M - 10a (2010); plates meeting JIS SCMV4-2, equivalent to ATSM A387 / A387M - 11 (2011); and seamless pipes meeting JIS STPA24, equivalent to ASTM A355 - 89 (2006; JIS SFVAF22B, JIS SCMV4-2, and JIS STPA24 are found in Tachibana 1997).

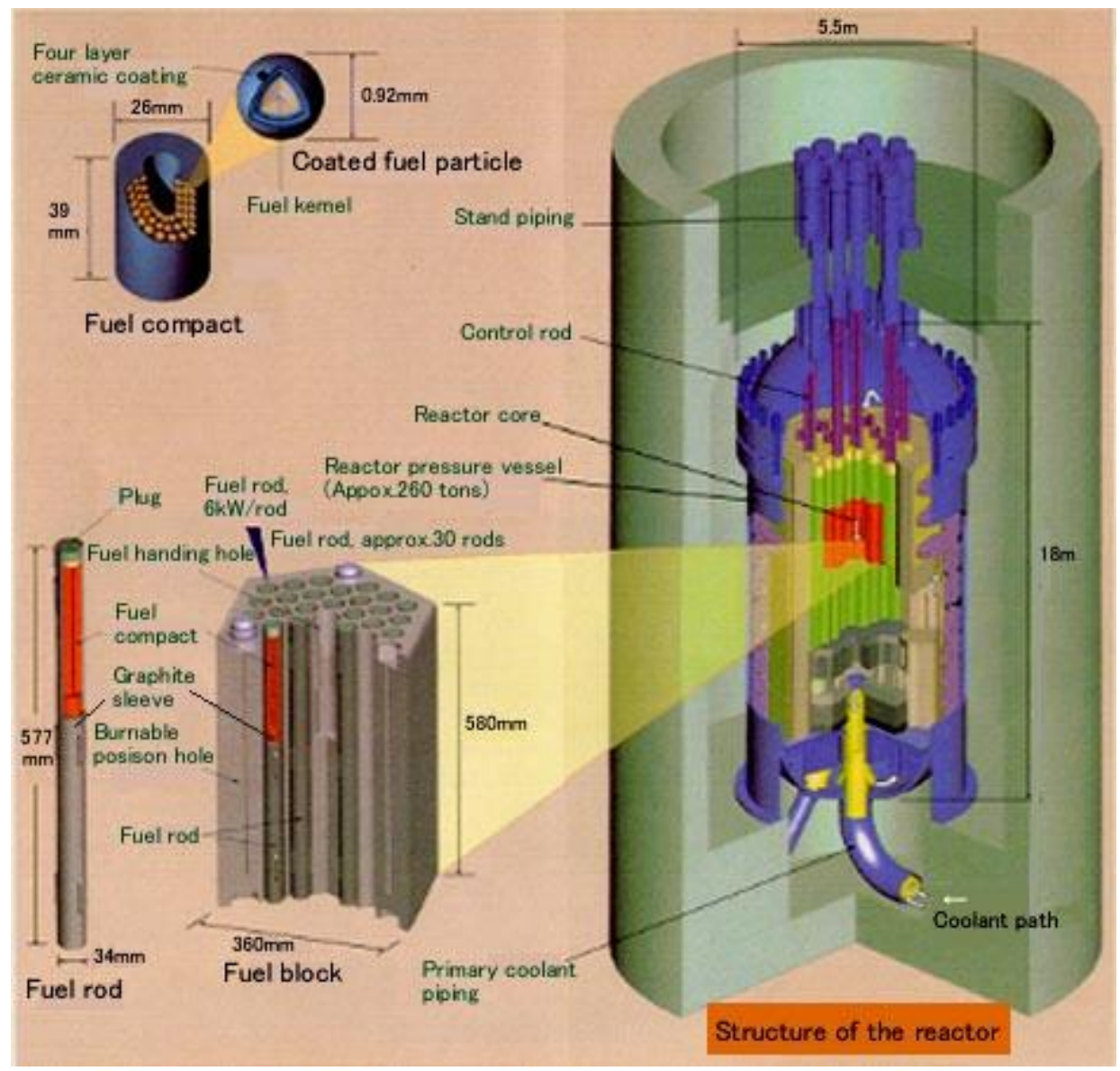


Figure 2. HTTR Fuel and Reactor Construction Details (Source http://www.jaea.go.jp/jaeri/english/ff/ff43/randd01.html)

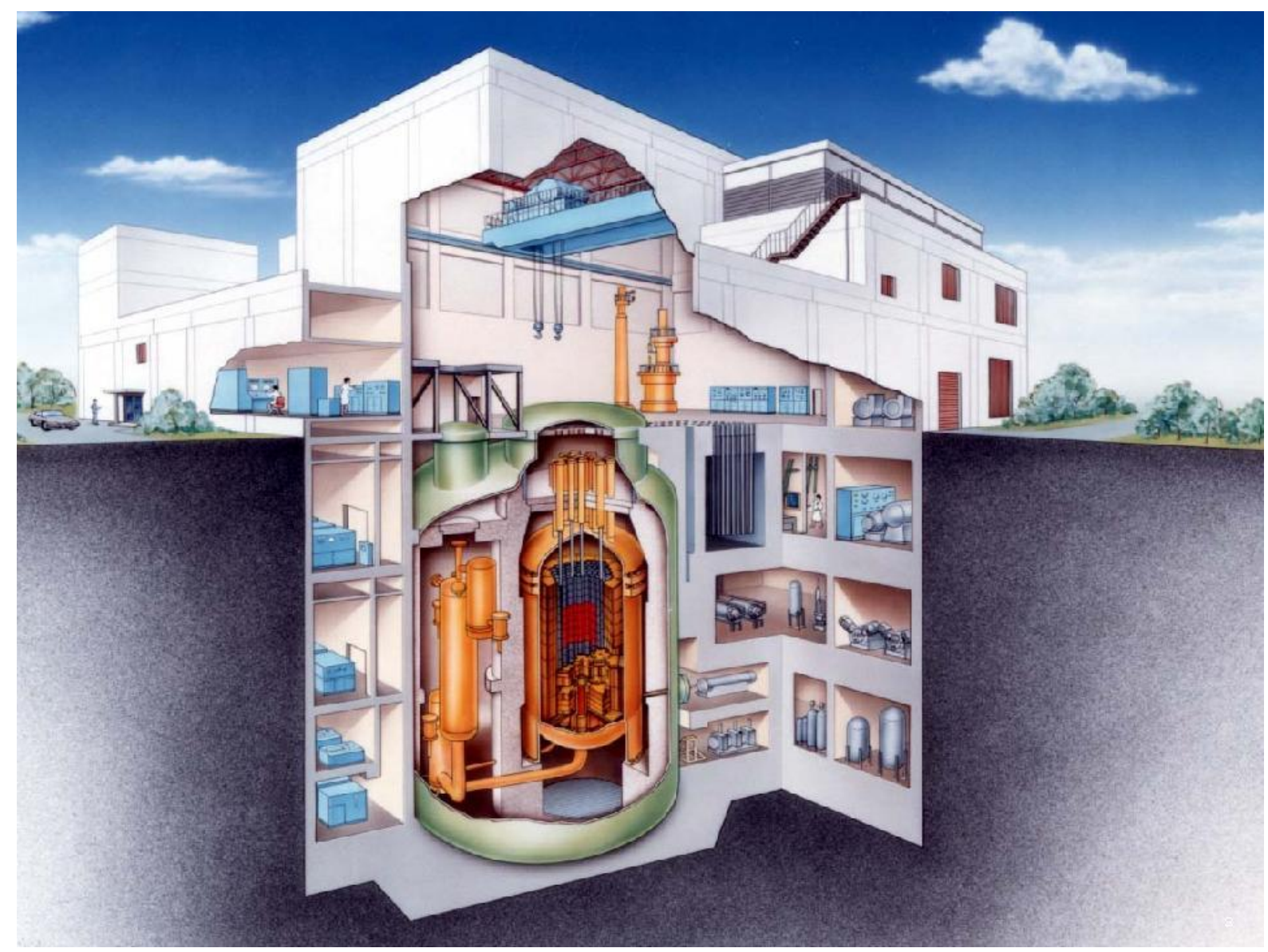

Figure 3. HTTR Plant Layout (Source: http:// http://httr.jaea.go.jp/eng/index.html)

\subsection{HTR-10 Plant Description}

Key Specifications (from Beck et al. 2010):

- Thermal Power: $10 \mathrm{MW}$

- Power Density: $2 \mathrm{MW} / \mathrm{M}^{3}$

- Secondary Coolant: Steam

- Primary System Pressure: $3 \mathrm{MPa}$

- Primary Inlet Temperature: $250 \mathrm{C}$

- Primary Outlet Temperature: $700 \mathrm{C}$

- Vessel Material: C-Mn-Si Steel (Yu 2011)

- Core Type: Pebble Bed

- Years of Operation: Start-up in 2000, still operating as of date of report (2011) 
HTR-10 is a helium-cooled, pebble-bed reactor, located at Tsinghua University in Beijing, China, very similar in construction to the Siemens design for a HTR module (Wu et al. 2002). The overall layout of a reactor vessel, a power conversion vessel, and a "cross-vessel" with a hot gas duct inside the cooler gas duct, is essentially the same design that has been used on several steel-vessel HTGR plants starting with Peach Bottom Unit 1. Some sources state that China does not have a specific licensing basis for HTGR reactors (Beck et al. 2010).

The overall layout of the plant is also similar to the proposed design of the GT-MHR. The three-vessel type design, with a hot duct inside a cross-vessel connecting the reactor and power conversion vessels, was first seen on Peach Bottom Unit 1 (which operated from 1966 to 1974). HTR-10 personnel refer to the connection between the reactor and power conversion vessels as a "vessel"; however, as noted below, they performed an LBB analysis on it as if it were considered a pipe.

As of 2011, the power conversion vessel contains a steam generator, but plans are in place to use an intermediate heat exchanger installed in an existing cavity in the power conversion vessel with a Brayton cycle turbine or to disassemble the steam generator and replace it with a direct Brayton cycle turbine. The indirect gas turbine could use either nitrogen or helium as a working fluid (Yuliang et al. 2011).

A paper presenting an LBB analysis for HTR-10, which should be largely applicable to GT-MHR and PBMR plants, was presented at the Second International Topical Meeting on High Temperature Reactor Technology in Beijing, September 2004 (Shiozawa et al. 2004). This topic is discussed in more detail in Section 3 of this report.

The specific Chinese codes and standards that govern the HTR-10 RPV were not found in literature when this was written.

\subsection{Non-Nuclear Operating Experience Applicable to HTGR}

HTGR RPV conditions, in terms of pressure and temperature, are within the experience base for petrochemical pressure vessels (maximum normal temperature of $500 \mathrm{C}(930 \mathrm{~F})$ or less and upset temperatures of $565 \mathrm{C}(1050 \mathrm{~F})$ or less $)$. Petrochemical vessels in this type of service have useful working lives of 50 years or more, comparable to nuclear plant RPV. Furnace tubes, operating at $950 \mathrm{C}$ $(1740 \mathrm{~F})$ to $1150 \mathrm{C}(2100 \mathrm{~F})$, typically have a service life of 5 to 10 years. An ASME document (Sims 2010) includes a table summarizing the alloys used, vessel thicknesses, service conditions, and damage mechanisms experienced.

\subsection{Conclusion}

Considering the history of the seven HTGR plants reviewed in this report, only two plants-FSV and THTR - have been built with thermal power greater than $150 \mathrm{MW}$. Additionally, these two plants are reasonably regarded as the only two plants that had any expectation of commercial viability. The thirdmost powerful plant, Peach Bottom, was shut down and decommissioned at the end of its life as a prototype primarily because utility analysis indicated that it was too small to be commercially viable. (It ran reliably, however and the authors found no documented technical reasons that it could not have continued to run many more years had the utility chosen to do so.) 
Of these two plants, FSV did not operate reliably enough to generate a profit for Public Service of Colorado - or even to cover its own expenses. FSV also had a significant financial disadvantage in that the fuel assemblies used were unique to that plant and were supplied only by General Atomics; even if the plant had operated reliably the cost of fuel would have been higher per MWe than the LWR plants in the United States. The large HTGR plants that General Atomics sold in the early 1970s were to use the same fuel as FSV and would have provided greater fuel manufacturing volume, which could have provided some economies of scale — but these plants were cancelled.

THTR operated reliably and had few technical issues. As the trial period of operation came to a close, with its reduced liability on the utility for decommissioning and other costs, a political decision was made not to apply for a permanent operating license but to decommission under the more favorable terms of the existing license.

The experience with these two plants can reasonably be expected to be viewed quite unfavorably by financial professionals who will be involved in any new HTGR plant construction: to date, all HTGR projects have been financially unsuccessful, including the two larger-than-prototype plants that were intended to be profitable.

Experience with inherent safety and radiological issues have been much more positive. FSV typically had personnel exposure in terms of man-rem far below contemporary U.S. LWR experience, even in years when refueling and/or circulator maintenance were performed. For example in 1985, the year of the major control rod drive refurbishment, FSV was responsible for 35 person-rem of exposure; during that year pressurized water reactor plants averaged 425 and boiling water reactor plants averaged 800 personrem. For all the other years (from 1980 to 1988), FSV never exceeded three person-rem of personnel exposure (Brey 1991). In terms of operational safety, a definite conclusion is harder to reach because the number of reactors and reactor years of operation is small, but the greater thermal mass of the graphite moderator and much higher margin from normal operating temperature to threshold fuel failure temperature support the idea that HTGR plants feature improved inherent safety characteristics compared to LWR plants. Experiments conducted at AVR confirmed reactor shutdown due to thermal feedback even without scram and without fuel failure (Marnet et al. 1991).

Operational reliability was good for the small, simple plants like Peach Bottom and AVR but not good for FSV (Goodjohn 1991). THTR exhibited fair reliability for the brief operating life it had: $61 \%$ in 1987 and 52\% in 1988 (Baumer and Kalinowski 1991). The limited information available indicates that both HTTR and HTR-10 have had good availability since they were put into operation.

Non-nuclear experience in the petroleum processing industry indicates that vessels made from materials similar to those being proposed for HTGR RPV construction have useful service lives of 50 years or more when vessel temperature is maintained at or below $500 \mathrm{C}(930 \mathrm{~F})$, but metallic components routinely exposed to temperatures near $1000 \mathrm{C}(1830 \mathrm{~F})$ have useful working lives of only about 5 to 10 years (Sims 2010).

Of the seven plants reviewed, Peach Bottom in the United States, HTTR in Japan, and HTR-10 in China had or have components similar to the proposed connections between the RPV and a power conversion vessel for the GT-MHR. Peach Bottom had two such components, identified as "cross-vessels", connecting the reactor vessel to the two steam generators. The HTTR refers to the component connecting the RPV and the secondary heat exchange vessels as a "duct". The HTR-10 refers to the connection 
between the reactor and the power conversion system as a vessel; however their LBB analysis was performed as if it is a pipe. The HTTR and HTR-10 literature reviewed appears to have been translated from Japanese and Chinese respectively. In the author's opinion the difference in terminology may be an artifact of translation. Based on this review, the authors have formed the opinion that the component connecting the RPV and power conversion vessel has not been consistently defined in operating plants. 


\subsection{Discussion of LBB}

The current approach to LBB is primarily to permit the licensee to not consider dynamic effects associated with piping breaks in reactor coolant systems, such as pipe whip and jet impingement, which would be expected to be less energetic in a helium cooled rather than water cooled system (NRC 1996).

USNRC Regulatory Guide 1.45 recommends, but does not require, the use of at least three different methods to detect system leakage (IAEA 2008). This document applies to current LWR plants and recommends leak detection methods such as measurement of sump levels, humidity, and airborne radioactivity levels, which are not applicable to HTGR plants. In a General Atomics report from December 1980, the opinion is expressed that this regulatory guide is applicable to HTGR reactors; monitoring of reactor coolant pressure, containment pressure, temperature, or radioactivity; and PCRV penetration seal system flow for leak detection (Lewis 1980). The third monitoring option, penetration seal system flow, reflects the PCRV type construction typical of FSV and the large plants that were planned for the 1970s but never built (Delmarva, Fulton, etc.).

In contrast to current generation LWR plants, modular HTGR plants, including the GT-MHR, are designed to be able to withstand a loss of forced cooling, including a depressurized loss of forced cooling such as would happen after a large-break loss-of-coolant accident, without experiencing fuel failure. According to the manufacturer, the modular HTGR fuel does not exhibit significant fission product release below $2000 \mathrm{C}$ (3630 F); maximum peak temperature during licensing basis events is predicted not to exceed 1600 C (2910 F) (Silady and Simon 1992). If and when this claim can be proven to NRC's satisfaction, fuel failure could be assumed to not occur at modular HTGR plants in the event of a depressurized loss of forced cooling, and the overall consequences of this accident, particularly for offsite personnel, would be much less severe than it is for current generation reactor plants.

Zhengming and Shuyuan of Tsinghua University presented an LBB analysis at the Second International Topical Meeting on High Temperature Reactor Technology in Beijing, held in September 2004 (Zhengming and Shuyuan 2004). The HTR-10 reactor features a cross-vessel type design, similar to Peach Bottom and to the proposed GT-MHR. The cross-vessel was selected as the most likely part of the primary system to fail for the purpose of the analysis, which was done in accordance with NRC recommended methods. (The methods are described by NUREG/CR-4572, which is referenced by Zhenming and Shuyan [2004].) Zhenming and Shuyan concluded that detectable coolant leakage would occur from a postulated circumferential through-wall crack well before it propagated far enough to cause sudden failure. The details of how leakage would be detected, beyond greater than normal makeup flow required to maintain main coolant pressure, were not discussed in this paper (Zhenming and Shuyuan 2004).

The NRC Inspection Manual, Part 9900 states that the application of LBB analysis to NPP piping systems supports removal of pipe whip restraints, jet impingement barriers, and other equipment designed to address the dynamic effects of postulated ruptures in LWR piping systems, but does not change the approach to global effects such as containment pressurization, rises in temperature and humidity, and fluid inventory loss. It is not clear that the HTR-10 LBB analysis is being applied in the same way. The conclusion of the HTR-10 analysis states "...the possibility of brittle fracture (of the cross-vessel) can be excluded." This seems to the authors to imply if not directly assert that a large-break LOCA is not considered a credible accident scenario at HTR-10. 
Given an acceptable LBB analysis and assuming acceptability of the analysis above indicating that a loss of forced cooling would not result in fuel failure or significant offsite release, it may be possible to treat a large-break LOCA in an HTGR quite differently from the current approach for LWR plants 


\title{
4.0 Materials, Codes, and Standards
}

Several candidate materials are under consideration for most of the structures, systems, and components at modular HTGR plants. At the time of this writing, more attention is being paid to SA-508/SA-533 and to modified 9Cr-1Mo steels for the RPV, power conversion vessel, and cross-vessel. For pebble bed modular reactor plants, as of 2009 the design called for SA-508 Grade 3 steel, with a normal operating temperature of $300 \mathrm{C}(572 \mathrm{~F})$, with design basis events bringing the vessel to as high as $430 \mathrm{C}(806 \mathrm{~F})$. The GT-MHR design calls for modified 9Cr-1Mo ASME Grade 91 steel, with normal temperature of 400 to $460 \mathrm{C}(752$ to $860 \mathrm{~F})$ and with temperature excursions as high as $570 \mathrm{C}$ (1058 F) (Makhele-Lekala et al. 2005).

Review and Assessment of Codes and Procedures for HTGR Components (NUREG/CR-6816) and Materials Behavior in HTGR Environments (NUREG/CR-6824) were written in 2003. NUREG/CR6816 reviews and evaluates currently available national and international codes and procedures for use in the design of high-temperature gas-cooled reactors (HTGRs). NUREG/CR-6824 reviews and evaluates data currently available on materials performance and long-term behavior in High-Temperature GasCooled Reactors (HTGRs),

ASME BPVC-XI-2-2007 was developed to govern in-service inspection and testing of the pressurecontaining components of gas-cooled reactors (Fisher and Orvis 1981).

ASME has issued a "roadmap" document (Sims 2010) outlining research and development as well as code development tasks considered necessary to support HTGR reactor construction, primarily aimed at supporting the Next Generation Nuclear Plant (NGNP). As part of this effort, ASME is planning to issue a new Division 5 of Section III of the Boiler and Pressure Vessel Code for components exceeding the temperatures in ASME BPVC III-1 - specifically ferritic materials up to $370 \mathrm{C}$ (700F), austenitic/high nickel materials up to $425 \mathrm{C}(800 \mathrm{~F})$, and graphite based materials. At the time of this writing, release of ASME BPVC-III-5-2011 is scheduled for October 31, 2011 (Sims 2010).

\subsection{Classification of Components, Nameplates, Stampings, and Reports}

Components are not classified by the Boiler and Pressure Vessel Code as evidenced by NCA-2110(c) in ASME BPVC-III-NCA, which states:

\begin{abstract}
While providing for several classes of construction (NCA-2120, NCA-2130), this Section does not provide guidance in the selection of a specific classification to fit a component in a given system. Such guidance is derived from systems safety criteria for specific types of nuclear power systems, such as pressurized water reactors, boiling water reactors, or high temperature gas cooled reactors, and may be found in engineering standards or in the requirements of regulatory and enforcement authorities having jurisdiction at the nuclear power plant site.
\end{abstract}

ANS-53.1-201x., Nuclear Safety Design Process for Modular Helium-Cooled Reactor Plants, (In Draft), is currently within the ANS Projects at Ballot process, meaning completed drafts have been issued for formal consensus committee ballot with concurrent public review. This document defines the process for specifying criteria to assure that modular helium-cooled reactor plants are designed to be constructed and 
operated safely without undue risk to public health and safety. This purpose is achieved through the identification of applicable safety requirements from the national nuclear regulator, industrial codes and standards, and other published guidance and professional engineering practices. ANS-53.1-201x will provide a process for establishing top-level safety criteria; safety functions; top-level design criteria; licensing basis events; design basis accidents; safety classification of systems, structures, and components; safety analyses; defense-in-depth; and special treatment requirements.

Since the ASME BPVC does not classify components, the authors anticipate that if and when endorsed by the NRC, ANS-53.1-201x will be used by industry to classify HTGR components. In the mean time, the DOE NGNP program has and is evaluating methods for classifying HTGR reactor plant components.

ASME BPVC-III-NCA, Article 1210 (“Components") requires each component of a nuclear power plant to have data reports and stamping as required in ASME BPVC-III-NCA Article 8000.

\subsection{ASME Code Rules Roadmap for HTGR Plants}

Current ASME codes do not adequately cover the construction of HTGRs. Although the current codes could be revised to meet the need, it has been recommended by ASME Standards Technology in Sims (2010) that a complete set of codes be developed specifically for HTGRs and other advanced reactor designs to cover new construction and in-service inspection.

The roadmap completed by Sims (2010), sponsored by NRC and the ASME Standards Technology, has been developed as a guide to the research and development and code development committees' tasks that could be useful in developing codes and standards for HTGRs. The primary focus of the roadmap is on the development of a complete set of rules for the design and operating conditions that are being proposed for the NGNP demonstration unit. In addition, Phase II activities are envisioned under this roadmap to develop rules for future generations of VHTGRs that are expected to operate at higher temperatures and for other advanced reactors such as liquid metal (e.g., sodium) cooled designs. Phase II activities are not included in the roadmap.

Some assumptions used in developing the roadmap (Sims 2010) include:

- Currently available technology and materials data, or data that can be obtained with relatively shortterm research and development programs, will be used to develop the code rules for elevated temperature metallic components.

- Rules for new construction of HTGRs will be contained in ASME BPVC-III-5-2011. ASME BPVC III-5 will reference existing material in other divisions and subsections as appropriate. ASME BPVCIII-5 - 2011 will be available in October 2011. This new code will provide construction rules for high-temperature reactors, including both HTGRs and liquid-metal reactors. These rules are for components exceeding the temperature in ASME BPVC III-1 and are meant for components experiencing temperatures that are equal to or higher than $370 \mathrm{C}(700 \mathrm{~F})$ for ferritic materials or 425 C (800 F) for austenitic stainless steels or high nickel alloys. Division 5 also contains new rules pertaining to graphite core components. These new rules include general requirements, plus design and construction rules, for graphite. Irradiation effects on graphite are addressed, as are the features of probabilistic design reflected in the determination of graphite material strength properties.

- Rules for in-service inspection and repair of HTGRs will be contained in ASME BPVC-XI-2-2007. 
- Rules and guidelines for operation and maintenance of nuclear power plants including pre-service and in-service testing will be contained within the existing ASME OM Code.

- Rules for probabilistic risk assessment will be contained in the new Standard for Probabilistic Risk Assessment for Advanced Non-LWR Nuclear Power Plant Applications. A draft dated October 2008 has been issued.

As can be seen with the issuance of ASME BPVC-XI-2-2007, the pending issuance of ASME BPVC-III5-2011, and the Standard for Probabilistic Risk Assessment for Advanced Non-LWR Nuclear Power Plant Applications, the industry is actively pursuing the codes, standards, and supporting documents required for design, construction, pre-service, and in-service testing and operation of HTGRs.

Several candidate materials are discussed below along with the applicable codes/standards and temperature limits.

\subsection{Metals}

SA-508/SA-533 steel has been used for LWR RPVs in the United States and abroad, and more than 40 years of experience have been accumulated using this alloy in the nuclear industry. The weldability, toughness, and thermal aging properties of this material have been improved over the years by limiting the allowable carbon content and by reducing the levels of sulfur and phosphorus impurities. This alloy is ASME Code Section III approved for Class 1 nuclear components; subsection NB rules are applicable up to $371 \mathrm{C}$ (700 F) (Simon 2010).

Modified 9Cr-1Mo steel is being considered for GT-MHR vessel applications (Beck et al. 2010) and is under consideration for core support structures in the NGNP HTGR. This alloy is ASME BPVC-III approved for Class 1 nuclear components; ASME BPVC-III-NB rules are applicable up to 371C (700 F) and ASME BPVC-III-NH rules are applicable to $649 \mathrm{C}$ (1200F). For the NGNP application, temperatures are not expected to exceed $350 \mathrm{C}(662 \mathrm{~F})$. The ASME Code covers this alloy in terms of high-temperature strength, creep, and stress rupture but does not cover emissivity, corrosion, thermal aging, and irradiation effects. These latter characteristics will require additional qualification before this material can be used in HTGR plants (Simon 2010).

A similar alloy, 2.25Cr-1Mo steel, was used to build the RPV for HTTR in Japan (Beck et al. 2010). It was used for the economizer-evaporator sections of the FSV once-through steam generators (below the bimetallic weld with Alloy 800 superheaters). This alloy is under consideration for similar use in the NGNP steam generators and for possible use in the construction of the steam generator vessel. The allowable stress for $2.25 \mathrm{Cr}-1 \mathrm{Mo}$ is similar to modified $9 \mathrm{Cr}-1 \mathrm{Mo}$ up to about $430 \mathrm{C}$, (806 F) but its strength drops off significantly above this temperature when compared to modified 9Cr-1Mo (Simon 2010).

Alloy $800 \mathrm{H}$ is one candidate for the hot duct (cross vessel) and other metallic components in contact with helium exiting the core. High temperature strength and creep/stress rupture for this alloy are covered by ASME Code Case N-201-5 (cited in Simon 2010) for core support structures, and ASME BPVC-III-NH covers Class 1 components. Up to about $427 \mathrm{C}(800 \mathrm{~F})$, there are no significant time dependent effects on allowable stress, up to a component life of 300,000 hours. Since some non-structural components could see temperatures of $800 \mathrm{C}(1472 \mathrm{~F})$ or higher, allowable stress limits will need to be extended. Studies 
sponsored by ASME Standards and Technology indicate that current information can support extending maximum use temperature to $850 \mathrm{C}(1562 \mathrm{~F})$ and maximum lifetime to 500,000 hours (Simon 2010).

Alloy $\mathrm{X}$ and alloy $\mathrm{XR}$ are being considered for core and core support structures that can see temperatures above $750 \mathrm{C}(1382 \mathrm{~F})$ during normal operation. Alloy $\mathrm{X}$ is a nickel-chromium-iron-molybdenum alloy that has favorable high temperature strength, corrosion resistance, and ease of fabrication. Alloy $\mathrm{X}$ is the older version, and is covered by ASME codes, but contains enough cobalt to raise activation concerns. Alloy XR is a proprietary version developed by the Japan Atomic Energy Agency for HTTR, with lower limits on cobalt. Alloy X is permitted to operate up to $427 \mathrm{C}(800 \mathrm{~F})$ according to ASME Section III and up to $899 \mathrm{C}(1650 \mathrm{~F})$ according to ASME Section VIII, a non-nuclear code that can be considered useful guidance (Simon 2010).

Type $316 \mathrm{H}$ stainless steel is being considered for core barrel assemblies and other metallic reactor internal components that would experience temperatures up to $620 \mathrm{C}(1148 \mathrm{~F})$. This alloy is a cost-saving substitute for alloy 800 and alloy X/XR where steam-side corrosion potential can be controlled (stress corrosion cracking). Type $316 \mathrm{H}$ stainless steel is covered by ASME BPVC-III-NB (Class 1 components and core support structures) up to $427 \mathrm{C}(800 \mathrm{~F})$. Type 316 and similar type 304 stainless have been commonly used for LWR reactor internal components. ASME BPVC-III-NH and Code Case N-201-5, extensions to Subsections NB and NG respectively, (cited in Simon 2010) extend temperatures up to 816 C (1500 F) (Simon 2010).

Alloy 617 has superior strength and creep resistance compared to alloy 800 or alloy X/XR above $800 \mathrm{C}$ $(1472 \mathrm{~F})$, and is often used in aircraft type gas turbines. Alloy 617 has 10 to $15 \%$ cobalt content by weight, making activation a concern. This alloy was studied for HTGR applications in the United States and Germany during the 1970s and 1980s. It has been studied extensively by Huntington Alloys, Oak Ridge National Laboratory, and General Electric, and the Huntington data have been used to develop ASME Code applications in Section I, Section VIII Division 1, and a Draft Code Case for Section III of the ASME BPVC. Alloy 617 is not qualified for use in ASME Code Section III, and work on the Draft Code Case was terminated when very high temperature reactor programs were terminated. (Simon 2010)

\subsection{Graphite}

To date, HTGR designs have featured not only graphite moderators as part of fuel assemblies - prismatic or pebble bed — but also graphite reflectors and structural materials near the core.

To date, relatively little guidance has been published on establishing regulatory or ASME code requirements on nuclear-grade graphite. The nuclear grade graphite materials used in past designs and plants are no longer available. Several major suppliers have proposed new graphite grades for nuclear use; these are discussed in Simon (2010) and in NUREG/CR-6824. Development of ASME codes related to nuclear grade graphite is also discussed in Sims (2010). Rules for new construction of HTGRs will be contained in ASME BPVC-III-5-2011. ASME BPVC-III-5 will be available in October 2011. This new code will provide construction rules for high-temperature reactors, including both HTGRs and liquidmetal reactors. Division 5 also contains new rules pertaining to graphite core components. These new rules include general requirements, plus design and construction rules, for graphite. Irradiation effects on graphite are addressed, as are the features of probabilistic design reflected in the determination of graphite material strength properties. 


\subsection{Foreign Codes and Standards}

SECY-03-0047 addressed a number of key policy issues related to non-LWR license applications. In this paper, direction to staff regarding foreign codes and standards is given:

Review international codes and standards only as part of an application or preapplication review. The staff should gain experience through review of international codes and standards during the pre-application and application reviews of non-LWRs then apply the lessons-learned from these reviews to their activities involving our domestic codes and standards committees.

Additional foreign standards were not available and therefore were not reviewed. 


\subsection{Cross-Vessel vs. Cross-Duct Issue}

NUREG-1338, Draft Preapplication Safety Evaluation Report for the Modular High-Temperature GasCooled Reactor, Section 5.2.1 ("Design Description and Safety Objectives") states: "Application is also being made to the Code Committee to confirm DOE's proposed approach to design of the cross-duct as a vessel meeting ASME Code, Section III."

Review of ASME BPVC-III interpretations issued since 1989 did not find a published response. Either this interpretation was not submitted to the ASME, the ASME Boiler and Pressure Vessel Committee has not yet responded, or the Committee plans to address the Interpretation in future revisions to the ASME BPVC.

Review of the current edition of the 2010 ASME Section III, Rules for Construction of Nuclear Facility Components (2011 Addenda), provides the following rationale for the belief that the ASME would not define the cross-duct a vessel or a pipe, but rather leave it to the owner to provide the design criteria (i.e., vessel or pipe) within the Design Specification.

The forward in ASME BPVC-III-NCA, states:

The Code Committee does not rule on whether a component shall or shall not be constructed to the provisions of the Code. The Scope of each Section has been established to identify the components and parameters considered by the Committee in formulating the Code rules.

The cross-duct would be considered a component as defined in ASME BPVC-III-NCA, Article 9000 ("Glossary"), which defines a component as: "a vessel, concrete containment, pump, pressure relief valve, line valve, storage tank, piping system, or core support structure that is designed, constructed, and stamped in accordance with the rules of this Section."

ASME BPVC-III-NCA, NCA-1210 (“Components"), requires each component of a nuclear power plant to have a Design Specification (ASME BPVC-III-NCA, Subsubarticle 3250), a Design Report (ASME BPVC-III-NCA, Subsubarticles 3350 and 3550), and other design documents specified in ASME BPVCIII-NCA, Article 3000.

ASME BPVC-III-NCA, NCA-3251 ("Provision and Correlation"), states it is the responsibility of the owner to provide, or cause to be provided, Design Specifications for components, supports, and appurtenances. ASME BPVC-III-NCA, NCA 3252(a) ("Contents of Design Specifications"), states that the design specifications must contain sufficient detail to provide a complete basis for Division 1 construction.

In the mid-1980s, the NRC began to accept the concept of LBB for large-diameter, high-quality piping systems as a means of enhancing the safety of nuclear power plants. In Roadmap to Develop ASME Code Rules for the Construction of High Temperature Gas Cooled Reactors (HTGRS), ASME suggests that LBB criteria be included in ASME BPVC-III-5-2011 (Sims 2010). Assuming ASME BPVC-III-5-2011 does include new rules for LBB that are applicable to the cross-vessel, it would follow that the code considers the cross-vessel as piping. 
It is the authors' opinion that the ASME Boiler and Pressure Vessel Code-designed cross-vessel could be constructed as a vessel or as a pipe. (Construction as defined by the ASME BPVC is an all-inclusive term comprising materials, design, fabrication, examination, testing, inspection, and certification required in the manufacture and installation of an item.) However, a vessel is normally considered to have nozzles and closure heads, neither of which are present on the preliminary designs reviewed for the cross-vessel. In the "Technology Integration Review for NGNP Air Ingress Workshop Record," March 31 \& April 1, 2009 , it is recognized that an understanding of how the cross-duct will actually behave is necessary. Compared to the two vessels, the duct (designed as vessel) may look and respond more like a pipe. Further, ASME Standards Technology, in Roadmap to Develop ASME Code Rules for the Construction of High Temperature Gas Cooled Reactors (HTGRS), suggested that LBB criteria be included in the new ASME BPVC III-5 (Sims 2010). Assuming ASME BPVC III-5 does include new rules for LBB that are applicable to the cross-vessel, it would follow that ASME BPVC III-5 may consider the cross vessel as piping.

Whether this component is called a cross-duct, cross-vessel, or pipe, the owner defines in its design specifications to which ASME BPVC subsection or division (NB, NC, ND, NE, NF, NG, NH, Division 1, or Division 5) it is designed. Overpressure protection will be required by the rules of ASME BPVC-IIINCA.

A review follows of ASME BPVC-III-NH to identify the differences in Code requirements for a component constructed as a vessel or as a pipe.

ASME BPVC Article NH-3000, Design_NH-3111.1 Acceptability, states:

An acceptable design of a Class 1 Component for elevated temperature service is one which:

(a) is capable of meeting the functional requirements as specified in the Design Specifications (NCA-3250); and

(b) satisfies the requirements for a design by analysis, either in NH-3200 or in the Design Rules for components, while under the loadings described in NH-3111.2 and the Design Specifications; and

(c) satisfies the general design rules of $\mathrm{NH}-3130$ and the applicable design rules for components that apply to a vessel (NH-3300), pump (NH-3400), valve (NH-3500), or piping (NH3600). The Design Specifications shall state which Subarticle applies to the given component.

ASME BPVC Article NH-3130, General Design Rules, paragraph NH-3136, Reinforcement for Openings, states: see NH-3330 and NH-3643 for the rules applicable to reinforcement of openings in the pressure boundaries of vessels and piping, respectively. However, NH-3331, General Requirements for Openings, subparagraph NH-3331(c) states if it is shown by analysis that all of the requirements of NH3200 have been met for the structural material near an opening, then the rules of NH-3332 through NH3339 are waived. When allowed to waive NH-3332 through NH-3339 the remaining rules of NH-3300 concerning welded construction are the same as for piping in NH-3600, Piping Design. The only remaining rule affecting only vessels (NH-3661) is for tapered transitions in vessels which is not addressed in NH-3600 and would normally not be applicable to piping.

Additionally, ASME BPVC III-NH rules in Subarticle NH-3600 Piping Design, versus Subarticle NH3300 Vessels, that may be applicable to the cross vessel are Subsubarticles NH-3620 Design Considerations and NH-3670 Special Piping Requirements. NH-3620 provides rules for dynamic effects which include impact, earthquake vibration, weight effects and loadings, displacements and restraints. NH-3670 includes rules for expansion and flexibility. Similar rules are not included in NH-3300. 
However, the additional rules of NH-3620 would be expected to be addressed for vessels in NH-3100 General Requirements for Design. What is concluded from the preceding paragraphs is that the ASME $\mathrm{BPVC}$ rules for construction of pipe may be more specific than for a vessel.

The authors conclude the ASME BPVC would allow the cross-duct to be constructed as a vessel or pipe, but consider it more appropriate to design the cross-vessel as a pipe, similar to current LWR methodology. However, with the preceding statement, it is suggested that review of ASME BPVC-III-52011 design and LBB criteria be performed when ASME BPVC-III-5-2011 is available. If ASME BPVC-III-5-2011 does not adequately answer the issue, then it is suggested that an ASME interpretation be submitted to the ASME Section III committee for resolution when designs are solidified. 


\subsection{Overpressure Protection}

ASME BPVC-III-NCA, NCA-3271, Responsibility and Content, requires the owner to provide, or cause to be provided, an overpressure protection report for each component or system (ASME BPVC-III-NB, NB-7200; ASME BPVC-III-NC, NC-7200; or ASME BPVC-III-NE, NE-7200).

ASME BPVC-III-NH, NH-3137.2, Design Consideration for Overpressure Protection of the System, requires each component and the system into which it will be installed to be protected against overpressure events as required by the rules on overpressure protection of Class 1 components and systems exposed to elevated temperature service. It is assumed that ASME BPVC-III-5-2011 will require overpressure protection requirements similar to ASME BPVC-III-NH, NH-3137.2. If these rules for overpressure protection are not included in ASME BPVC-III-5-2011, then the rules of ASME BPVC-IIINCA, NH-3271 would still require overpressure protection to be addressed in the owner's overpressure protection report. 


\subsection{Conclusion}

This document reviews the operating history of past and present HTGR plants, assesses the currently available literature related to codes and standards applicable to HTGR plants and evaluates the proposed designs of RPV and associated piping for future plants.

The operational histories of five decommissioned and two currently operating HTGR plants were reviewed, leading the authors to conclude that while small, simple prototype HTGR plants operated reliably, some of the larger plants (particularly FSV) had poor availability. Safety and radiological performance of these plants has been considerably better than LWR plants. The full potential of HTGR plants for electrical generation has not yet been demonstrated in practice. Pebble-bed and prismatic block HTGR reactor cores have both been built, and both designs appear to be practical. Of the seven reactors, Peach Bottom, HTTR, and HTR-10 were built with cross-vessels.

Petroleum processing plants provide some applicable experience with materials similar to those proposed for HTGR piping and vessels.

At least one currently operating plant-HTR-10 - has performed and documented an LBB analysis that appears to be applicable to proposed future U.S. HTGR designs. This analysis was performed in accordance with NUREG/CR-4572 and concluded that the HTR-10 cross-vessel would exhibit detectable leakage before any through-wall crack grew to critical size.

Current codes and standards cover some HTGR materials, but not all materials are covered to the high temperatures envisioned for HTGR use. Codes and standards, particularly ASME codes, are under development for proposed future U.S. HTGR designs. A "roadmap" document (Sims 2010) has been prepared for ASME code development, and a new Division to Section III of the ASME BPVC, ASME BPVC-III-5-2011, is scheduled to be published in October 2011.

The question of terminology for the cross-duct structure between the RPV and power conversion vessel was examined, considering the important differences in regulatory requirements that apply depending on whether this structure is designated as a "vessel" or as a "pipe." The authors concluded that designing this structure as a pipe is the more appropriate choice but that the ASME BPVC code allows the owner of the facility to select the preferred designation, and that either designation can be acceptable. 


\subsection{References}

10 CFR 50. Code of Federal Regulations, Title 10, Energy, Part 50, "Domestic Licensing of Production and Utilization Facilities."

ANS-53.1-201x. In Draft. Nuclear Safety Criteria and Safety Design Process for Modular HeliumCooled Reactor Plants. American Nuclear Society, La Grange Park, Illinois.

ASME BPVC-III-NB. 2010. Class 1 Components. American Society of Mechanical Engineers, New York, New York.

ASME BPVC-III-NC. 2010. Class 2 Components. American Society of Mechanical Engineers, New York, New York.

ASME BPVC-III-NCA. 2010. General Requirements for Division 1 \& Division 2. American Society of Mechanical Engineers, New York, New York.

ASME BPVC-III-NE. 2010. Class MC Components. American Society of Mechanical Engineers, New York, New York.

ASME BPVC-III-NH. 2010. Class 1 Components in Elevated Temperature Service. American Society of Mechanical Engineers, New York, New York.

ASME BPVC-XI-2-2007. 2007. Rules for Inservice Inspection of Nuclear Power Plant Components. American Society of Mechanical Engineers, New York, New York.

ASME OM, 2011. Operation and Maintenance of Nuclear Power Plants, American Society of Mechanical Engineers, New York, New York.

ASTM A336/A336M - 10a. 2010. Standard Specification for Alloy Steel Forgings for Pressure and High-Temperature Parts. American Society for Testing and Materials, Philadelphia, Pennsylvania.

ASTM A355 - 89(2006). 2006. Standard Specification for Steel Bars, Alloys, for Nitriding. American Society for Testing and Materials, Philadelphia, Pennsylvania.

ATSM A387 / A387M - 11. 2011. American Society for Testing and Materials, Philadelphia,

Pennsylvania. Standard Specification for Pressure Vessel Plates, Alloy Steel, Chromium-Molybdenum. American Society for Testing and Materials, Philadelphia, Pennsylvania.

Baumer R and I Kalinowski. 1991. "THTR commissioning and operating experience.” Energy 16(12):59-70.

Beck JM, CB Garcia, and LF Pincock. 2010. High Temperature Gas-Cooled Reactors Lessons Learned Applicable to the Next Generation Nuclear Plant. INL/EXT-10-19329, Idaho National Laboratory, Idaho Falls, Idaho. 
Benham RG, A Nathan, and JR Reesy. 1973. "Electrical Design of the Fort Saint Vrain Nuclear Generating Station." IEEE Transactions on Power Apparatus and Systems PAS-92(1):42-49. ASME BPVC-III-5-2011. In Draft. ASME BPVC Section III-Rules for Construction of Nuclear Facility Components-Division 5-High Temperature Reactors. American Society of Mechanical Engineers, New York, New York.

Brey HL. 1991. "Fort St. Vrain operations and future.” Energy 16(1-2):47-58.

Daniels F. 1944. Suggestions for a High-Temperature Pebble Pile. MUC-FD-8; N-1668b, Chicago University Metallurgical Laboratory, Chicago, Illinois.

Fisher CR and DD Orvis. 1981. "Licensing HTGRs in the United States." Proceedings from International Working Group on Gas-Cooled Reactors. International Atomic Energy Agency, Vienna, Austria.

Goodjohn AJ. 1991. Summary of Gas-Cooled reactor programs.” Energy 16(1-2):79-106.

Hoffman DP and LD Mears. 1991. “Outlook for MHTGR project development.” Energy 16(1-2):107110.

IAEA. 2008. Applicability of the Leak Before Break Concept. IAEA-TEC-DOC-710, revision 1, International Atomic Energy Agency, Vienna, Austria.

LER (License Event Report) 50-267/87-023. HV-2292 Oil Leak Caused Fire and Manual Scram. Public Service Co., Platteville, Colorado.

Lewis JH. 1980. Licensing Topical Report: Applicability of Division 1 Regulatory Guides to HighTemperature Gas-Cooled Reactors. GA-A16077, General Atomic Company, San Diego, California.

Makhele-Lekala L, P Ennis, and F Schubert. 2005. "Candidate Materials for Advanced HTGRS." In the Proceedings from $18^{\text {th }}$ International Conference on Structural Mechanics in Reactor Technology, SMiRT, Berlin, Germany.

Marnet C, G Ivens, and E Ziermann. 1991. “The AVR power plant in its last year of operation.” Energy 16(1-2):71-77.

NRC. 1996. "Part 9900: Technical Guidance.” NRC Inspection Manual. U.S. Nuclear Regulatory Commission.

NUREG/CR-4572. 1986. NRC Leak-Before-Break (LBB.NRC) Analysis Method for Circumferentially Through Wall-Cracked Pipes Under Axial Plus Bending Loads. R Klecker, FW Brust, and G Wilkowski. U.S. Nuclear Regulatory Commission, Washington, D.C.

NUREG/CR-6816. 2003. Review and Assessment of Codes and Procedures for HTGR Components. VN Shah, S Majumdar, and K Natesan. U.S. Nuclear Regulatory Commission, Washington, D.C.

NUREG/CR-6824. 2003. Materials Behaviors in HTGR Environments. K Natesan, A Purohit, and SW Tam. U.S. Nuclear Regulatory Commission, Washington, D.C. 
NUREG/CR-6839. 2003. Fort Saint Vrain Gas Cooled Reactor Operational Experience. DA Copinger and DL Moses. U.S. Nuclear Regulatory Commission, Washington, D.C.

NUREG-1338. 1989. Draft preapplication safety evaluation report for the modular high-temperature gas-cooled reactor. PM Williams, TL King, and JN Wilson. U.S. Nuclear Regulatory Commission, Washington, D.C.

SECY-03-0047, 2003. Policy Issues Related to Licensing Non-Light-Water Reactor Designs. , Travers WD. Nuclear Regulatory Commission, Washington, D.C.

Shiozawa S, S Fujikawa, T Iyoku, K Kunitomi, and Y Tachibana. 2004. "Overview of HTTR design features." Nuclear Engineering and Design 233(1-3):11-21.

Silady FA and WA Simon. 1992. Innovative safety features of the modular HTRGR. GA-A-20789-Rev. 1, General Atomics, San Diego, California.

Simnad MT. 1991. "The early history of high-temperature helium gas-cooled nuclear power reactors." Energy 16(1-2):25-32.

Simon P. 2010. NGNP High Temperature Materials White Paper. INL/EXT-09-17187, Idaho National Laboratory, Idaho Falls, Idaho.

Simon R. 2005. "The Primary Circuit of the Dragon High Temperature Reactor Experiment." In the Proceedings from $18^{\text {th }}$ International Conference on Structural Mechanics in Reactor Technology, SMiRT, Berlin, Germany.

Simon RA and PD Capp. 2002. "Operating Experience with the Dragon High Temperature Reactor Experiment." In Proceedings of the Conference on High Temperature Reactors. HTR-2002. International Atomic Energy Agency, Vienna, Austria.

Sims R. 2010. Roadmap to Develop ASME Code Rules for the Construction of High Temperature Gas Cooled Reactors (HTGRS). STP-NU-045, ASME Standards Technology, LLC, New York, New York.

Tachibana Y, K Kunitomi, S Shiozawa, T Asami, and S Yamaguchi. 1997. "Material and Fabrication of the HTTR Reactor Pressure Vessel." Proceedings from the technical committee meeting on high temperature gas cooled reactor technology development, IAEA-TECDOC--988, International Atomic Energy Agency, Vienna, Austria.

Wu Z, D Lin, and D Zhong. 2002. "The design features of the HTR-10." Nuclear Engineering and Design 218(1-3):25-32.

Yu S. February 19, 2011. "SA 516 steel.” Email message from Suyuan Yu.

Yuliang S, Z Yinguang, and X Yuanhui. 2001. "Study on Coupling a Gas Turbine Cycle to the HTR-10 Test Reactor." In the International Atomic Energy Agency Technical Committee Meeting on Gas Turbine Power Conversion Systems for Modular HTGRs. IAEA-TECDOC--1238. International Atomic Energy Agency, Vienna, Austria. 
Zhengming Z and H Shuyan. 2004. "Leak-Before-Break Analysis of the HTR-10's Hot-Gas Duct Vessel." In the Proceedings of the Conference on High Temperature Reactors. HTR-2004. International Atomic Energy Agency, Vienna, Austria. 


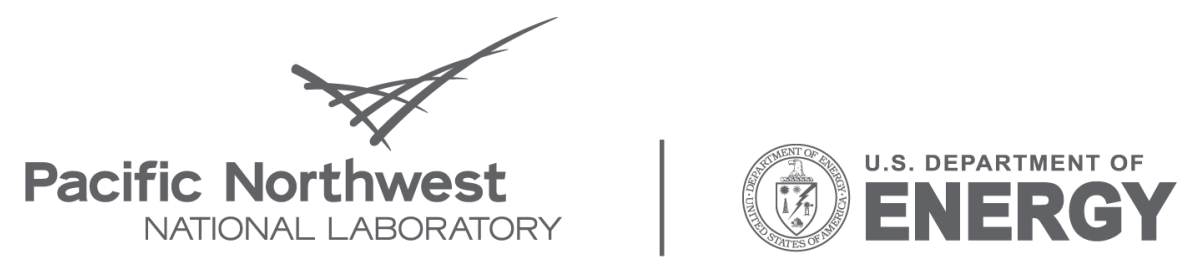

Proudly Operated by Battelle Since 1965

902 Battelle Boulevard

P.O. Box 999

Richland, WA 99352

1-888-375-PNNL (7665)

www.pnl.gov 